\title{
Servant Leadership and Follower Creativity Via Competence: A Moderated Mediation Role of Perceived Organisational Support
}

\author{
Nguyen Phan Hanh Thao and Seung-Wan Kang \\ Gachon University, Seongnam City, Gyeonggi-do, Republic of Korea
}

\begin{abstract}
Trser he precedents of creativity comprise an important research topic that could help organisations survive fierce competition. To contribute to the literature on creativity, the authors examined the roles of competence and perceived organisational support (POS) in the relationship between servant leadership and follower creative behaviour. The authors proposed and tested a moderated mediation model with data from leader-follower dyads collected in a Vietnamese engineering firm. The results showed that follower competence is a significant mediator of the relationship between servant leadership and follower creativity. Furthermore, POS has a moderated mediating role, such that the mediated relationship (i.e., servant leadership, competence, and creativity) is more salient under high POS than under low POS. Theoretical and practical implications are discussed.
\end{abstract}

Keywords: creativity, servant leadership, competence, perceived organisational support, moderated mediation

A significant stream of research has accentuated the useful and effective qualities of servant leadership (Greenleaf, 1970) in improving organisational performance and boosting organisational competitiveness. Servant leadership is a unique leadership style (Greenleaf, 1977; Russell \& Stone, 2002). Servant leaders are characterised by people-centred, altruistic, and selfless behaviours (Avolio, Walumbwa, \& Weber, 2009; Parris \& Peachey, 2013). Research findings in the leadership area have suggested that followers of servant leaders are more likely to be satisfied, dedicated, involved in their work, and high performing (Carter \& Baghurst, 2014; Liden, Wayne, Zhao, \& Henderson, 2008; Neubert, Kacmar, Carlson, Chonko, \& Roberts, 2008).

The relationship between servant leadership and employee creativity has been revealed to be significant, but for the empirical and theoretical foundations of this topic (e.g., mechanisms through which servant leaders impact employee creativity and the boundary conditions of this relationship), there is still a dearth of research (Hunter et al., 2013; Neubert et al., 2008; Yoshida, Sendjaya, Hirst, \& Cooper, 2014). The need for further analysis of how and in what contexts servant leadership motivates followers to extend their input in organisations by engaging in creative behaviours therefore should be addressed to further our knowledge of the way servant leaders impact individual behaviours and perceptions in an organisation.

This study aims to extend the literature in several ways. First, it examines the role of follower competence as a psychological mechanism by which servant leadership affects follower creativity. A previous literature (i.e., Yang, Liu, \& $\mathrm{Gu}, 2017$ ) examined the servant leadership and follower creativity link by studying the mediating mechanism of follower belief in their ability to perform creatively. Our study centres on employees' competence perception (i.e., work role-specific competence). Understanding the meaning of follower competence in this relationship will permit us to contribute to the theoretical validity and precision of servant leadership theory (Greenleaf, 1970, 1977; Liden et al., 2015) at the individual level. Second, by employing a moderated mediation test in the analysis of follower competence as the mediating mechanism and perceived organisational support (POS) as the moderator, we aim to highlight the pivotal influence of follower perception on organisation via follower competence and creative performance. This empirical examination is expected to add to the extant literature of creativity (Shalley, Zhou, \& Oldham, 2004) and leadership (Avolio et al., 2009) the 
salience of contexts and settings in strengthening servant leaders' potential. Given that the majority of servant leadership studies have been conducted in Western societies, our study is among the first to reveal its effect in a member country of the Asia Pacific region by applying a moderated mediation model. Last, by underlining the imperative function of leaders who express authentic interest in follower growth and in recognising and nurturing follower creativity, we contribute to follower-oriented leadership studies, including that of servant leadership (Greenleaf, 1970).

\section{Theoretical Background and Hypotheses} Servant Leadership and Follower Creativity

Servant leadership is a people-centred leadership concept that is characterised by an emphasis on others' interests and wellbeing as the leader's primary concern. Servant leaders become leaders because they have a passion for serving and encouraging good deeds within society (Graham, 1991). As a result, servant leaders in any organisation are known for their selfless focus, continuous investment in followers' growth, and absolute trust in followers, which render them great assets to organisational development (Stone, Russell, \& Patterson, 2004; van Dierendonck, 2011). Further, servant leadership involves a component of morality (Ehrhart, 2004; Russell \& Stone, 2002), such that all followers of servant leaders are treated in an equal and respected manner on principle (Graham, 1991). The distinction between servant leadership and other leadership theories (e.g., transformational leadership) has been discussed and proven in several studies (Ehrhart, 2004; Graham, 1991; Stone et al., 2004); for instance, the main focus of servant leaders and transformational leaders is distinguishable, servant leaders are more concerned about employee wellbeing, while transformational leaders are more concerned about organisational wellbeing (Stone et al., 2004).

Creativity is conceptualised as the perception-based analysis of the level of novelty and efficiency of products introduced by entities in organisations to deal with market challenges (Amabile, 1988, 1996; Shalley \& Gilson, 2004). This topic has received great attention and has been considered to be of profound importance in behavioural studies (Amabile, 1996), given its widely acknowledged role as a precondition for innovation (Amabile, 1988). More specifically, employee creativity has been studied intensively by scholars because it has been found to be significantly related with organisational survival (Woodman, Sawyer, \& Griffin, 1993), organisational competitiveness (Oldham \& Cummings, 1996), and organisational innovation (Amabile, 1988). Research in this field has suggested that social contexts in the workplace, and especially effective leadership styles such as servant leadership, are critical for cultivating creativity (Amabile \& Khaire, 2008; Carmeli, Gelbard, \& Reiter-Palmon, 2013; Neubert et al., 2008; Yoshida et al., 2014).
Recently, a number of studies have suggested that the relationship between servant leadership and individual performance can be mediated by other variables, such as promotion focus (Neubert et al., 2008), leader identification (Yoshida et al., 2014), commitment to supervisor (Walumbwa, Hartnell, \& Oke, 2010), and serving culture (Liden, Wayne, Liao, \& Meuser, 2014), which indicates the plausibility and importance of further investigation into the complicated mechanism of this relationship. In this study, we attempt to answer part of the intricate question by closely inspecting the role of follower competence in the relationship between servant leadership and follower creativity.

\section{Servant Leadership and Follower Competence}

Follower competence refers to followers' assessment of their ability to accomplish workplace tasks and followers having opportunities to perform and become proficient with their skills (Spreitzer, 1995). In this sense, leaders, as close relational constituents and pivotal elements constructing followers' understanding of workplace surroundings, are considered to constitute a decisive factor determining follower competence (Baard, Deci, \& Ryan, 2004; Deci, Schwarz, Sheinman, \& Ryan, 1981). Supportive leadership such as servant leadership is expected to be able to make a positive impact on follower competence (Spreitzer, 1995) because supportive leaders are capable of augmenting followers' task-related proficiency with their rational, ethical, and emotional decisions.

Servant leadership exhibits a competence empowerment process through leaders' recognition of followers' ability and realisation of followers' potential growth (Greenleaf, 1998). Genuinely caring acts, benevolence, and individualised consideration enable servant leaders to know what suits followers best, thus providing followers with a nurturing and favourable environment in which they are assisted in learning new skills, expanding their knowledge, reaching new high levels, and achieving their goals (Chen \& Bliese, 2002; Liden et al., 2015; Liden et al., 2008; Walumbwa et al., 2010). As a result, followers' confidence that they have gained sufficient expertise to fulfill their jobs is fostered. Consistent with this reasoning, Walumbwa et al. (2010) suggested that servant leaders provide guidance and enhance followers' competence through dissemination of knowledge and experience such that followers can solve job-related problems effectively. We also argue that follower competence is strengthened under the supervision of servant leaders because servant leaders are known for their goal clarification toward followers. While servant leaders encourage followers to take new responsibilities and tackle new challenges in their own way, servant leaders ensure that followers are aware of exactly what expectation is ahead, constantly providing practical feedback and letting followers have credit for their achievements (van Dierendonck \& Rook, 2010). 
Hypothesis 1: Servant leadership is positively related to follower competence.

\section{The Mediating Role of Follower Competence}

Studies in creativity have suggested that, in addition to leadership styles, follower creativity can be determined by follower competence (Amabile, 1988), which renders followers persistent in the face of adversity that is deeply rooted in creative work (Shalley \& Gilson, 2004). Indeed, a great deal of research has emphasised the strong association between follower competence and creative performance (Amabile, 1988; Shalley \& Oldham, 1997).

In this article, we posit that servant leadership not only enhances follower competence, but also enhances follower creativity through the process of enhancing follower competence, because when followers are confident about their ability to perform task assignments, they are empowered to engage in extra-role behaviours such as creativity (Spreitzer, 2008). More specifically, under the supervision of servant leaders, follower competence increases as followers perceive themselves to possess the capabilities necessary to create positive contributions if they put forth adequate effort. Follower competence then provides a critical boost for followers to exhibit creative behaviours.

First, servant leadership, as a supportive and peoplecentred form of leadership, facilitates new creative ideas by instilling competence in followers. Servant leaders, by establishing a developmental environment promoting highquality exchange, positive spirit, and constructive feedback aims to shift follower concentration from external matters to an internal force lying in the work itself (Deci, Connell, \& Ryan, 1989). Followers then experience an increasing level of competence, becoming more interested in their tasks, and focusing more on creative accomplishments. Second, servant leaders guide followers with informational directions and prompt assistance, and followers are more likely to feel competent and accomplish creative work (Redmond, Mumford, \& Teach, 1993). This notion originates in creativity-required contexts characterised by complex, vague, and under-developed issues that rely on servant leaders to set unambiguous goals, clarify expectations, and expedite discussion framing (Carmeli \& Schaubroeck, 2007; Mumford, Byrne, \& Shipman, 2009). Finally, the mediating role of follower competence in the relationship between servant leadership and follower creativity also manifests itself when servant leaders provide followers with the necessities demanded to implement creative tasks such as financial funding, materials, or knowledge sharing. Such necessities would be impossible for the follower to access without leaders' support as facilitators.

Hypothesis 2: Follower competence mediates the relationship between servant leadership and follower creativity.

\section{The Moderating Role of POS}

POS originated in the organisational support theory proposed by Eisenberger, Huntington, Hutchison, and
Sowa (1986), illustrating followers' global perception about organisational appreciation toward their work inputs and organisational consideration of their wellbeing (Eisenberger et al., 1986). Creative performance is inherently contextualised (Amabile, 1988; Mumford, Scott, Gaddis, \& Strange, 2002; Woodman et al., 1993), such that the driving force for follower creativity comes from followers' social and technical surroundings (e.g., pressures, resources, policies, and rewards; Caniëls, De Stobbeleir, \& De Clippeleer, 2014; Csikszentmihalyi, 1999).

In line with this argument, several studies have confirmed that followers' perceptions of their work environments impact followers' exhibition of creativity (Amabile, Conti, Coon, Lazenby, \& Herron, 1996; Oldham \& Cummings, 1996) because workplace cues play a role in shaping follower competence (Ford, 1996). The characteristics of work environments are not limited to proximal factors (i.e., employee daily work) but extend to distal factors (i.e., the organisational system and organisational procedures) in which organisations are viewed as a whole. Therefore, it can be suggested that although the role of supportive leaders is of critical importance for follower competence and creative performance, the role of organisational support in many manifestations should be considered complementary to that of leaders. When followers perceive goal alignment between servant leaders and their organisations in favour of their interests (i.e., followers receive all the assistance needed from both their immediate servant leaders and their organisations, for the same purpose), followers are expected to feel more competent regarding their task assignments and to be more likely to exhibit creativity.

Goal alignment between leaders and organisations is especially important in situations requiring creativity. For example, servant leaders may be aware that complex and demanding jobs are suggested to enhance follower competence, thus motivating them to perform creatively, more than jobs that are usually done in the same way (Hackman \& Oldham, 1980; Sagiv, Arieli, Goldenberg, \& Goldschmidt, 2010), but the responsibility to design and control job architecture is not always completely in the servant leaders' control. In fact, it may depend more on the position of leaders in the organisational hierarchy, the organisational structure, or organisational policies. Similarly, leaders rely on operating processes and rules that the whole organisation determine to decide how they interact and exert influence on followers. Even when leaders try to create an environment that is as positive and supportive as they can manage via public relations and boundary management, if the 'outside world' is characterised by the extravagant employment of strict regulations, inspections and discipline, follower creativity can still be inhibited (Shalley \& Gilson, 2004). In other words, followers may need access to different inputs and support from different individuals and groups within an organisation, not just from their immediate leaders, for the successful development and operation of creative works. The hypothetical research model for the study is depicted in Figure 1. 


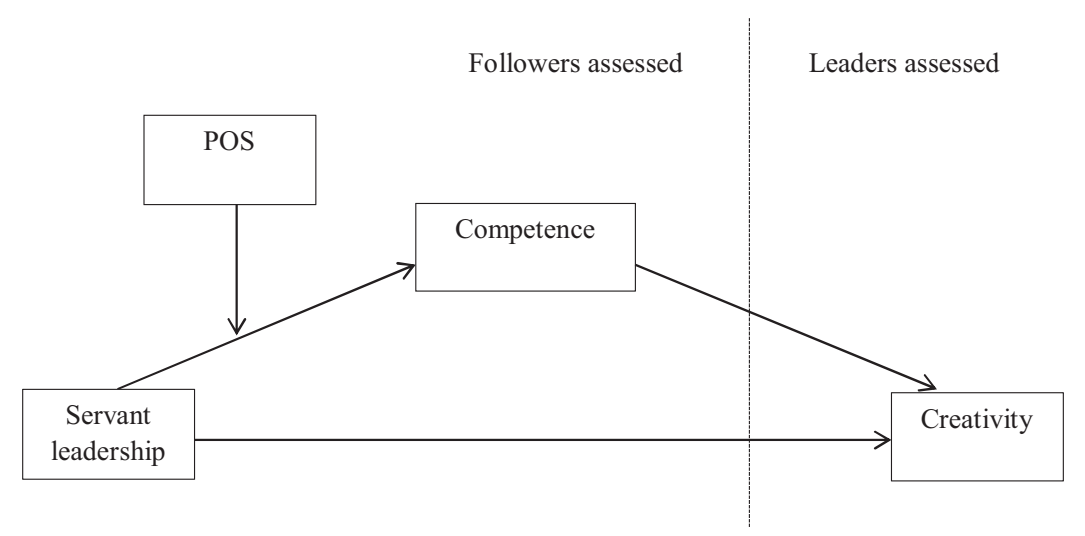

\section{Figure 1}

Hypothesised model.

Note: POS = perceived organisational support.

Hypothesis 3: POS moderates the strength of the mediated relationship between servant leadership and follower creativity via follower competence, such that the mediated relationship is more salient under high POS than under low POS.

\section{Methods}

\section{Sample}

We conducted a survey in a local engineering firm in Vietnam. The sample consisted of 148 participants (response rate of $89.7 \%$ ) with matched immediate leaders' ratings for their creativity. Six teams participated in the survey, with similar job duties according to the head of the Human Resources division of the firm. Each team was under the supervision of one leader. At the time of the survey, no team rotation in the firm had been conducted since participants were recruited.

The average follower age was 25 years, with mean work experience in the firm of nine months and mean working time under the current leader of eight months. The average team leader's age was 39 years, with mean work experience in a leadership position of approximately seven years. Among followers, $81.5 \%$ were male, and $18.5 \%$ were female. Among team leaders, $85.7 \%$ were male, and $14.3 \%$ were female. These data were utilised as a source for the servant leadership project conducted by the authors.

\section{Procedure}

Because the survey was conducted in Vietnam, we had the questionnaire translated from English into Vietnamese by two professional translators. The translation process followed Brislin's (1970) instructions for a back-translation method to provide sufficient quality for the translated version because the original measures were created for Western countries. A trained research assistant was recruited to deliver survey envelopes to subordinates and their leaders at the firm. Participants were fully informed that the study was conducted completely for research purposes.
Each employee was provided an envelope consisting of an introductory letter written by the authors, a questionnaire sheet, and a participant number. The participant numbers were created to assure the confidentiality of participants' identities. Similarly, envelopes distributed to team leaders included an introductory letter, questionnaire sheets, and a list of the names of their current subordinates. Participants were instructed by the research assistant to seal their envelopes immediately after finishing the questionnaire for confidentiality reasons. Two weeks after survey delivery, the research assistant returned to the organisation to collect the sealed response envelopes and submitted them to the researchers.

\section{Measures}

Servant leadership. We used a scale consisting of seven items from Liden et al. (2014), which was a shortened version of the full questionnaire developed by Liden et al. (2008). The shortened version is sufficient to reflect all seven dimensions of servant leadership (i.e., emotional healing, creating value for the community, conceptual skills, empowering, helping subordinates grow and succeed, putting subordinates first, and behaving ethically) because it comprises the highest loading item from every dimension of the original measure (Liden et al., 2008). Employees responded on the 7-point Likert scale, ranging from $1=$ strongly disagree to $7=$ strongly agree. Sample items included 'My leader gives me the freedom to handle difficult situations in the way that I feel is best' and 'My leader emphasises the importance of giving back to the community'. Cronbach's alpha was .86 (see Appendix for complete items).

Competence. We used the three-item scale suggested by Spreitzer (1995) to measure the competence dimension of the global construct of psychological empowerment. The original scale was developed by Johns (1986). Employees answered based on a 7-point Likert scale, ranging from $1=$ strongly disagree to $7=$ strongly agree. Sample items included 'I am confident about my ability to do my job' 
Table 1

Factor Loadings and Average Variance Extracted Statistics of Study Constructs

\begin{tabular}{llll}
\hline Construct & Item & Loadings & AVE \\
\hline Servant leadership & SL 1 & .72 & .55 \\
& SL 2 & .69 & \\
& SL 3 & .85 & \\
& SL 4 & .80 & \\
& SL 5 & .66 & .57 \\
Competence & SL 6 & .65 & \\
& SL 7 & .85 & \\
POS & COM 1 & .72 & \\
& COM 2 & .79 & \\
& COM 3 & .67 & \\
& POS 1 & .69 & \\
& POS 2 & .70 & \\
& POS 3 & .66 & \\
& POS 4 & .80 & \\
Creativity & POS 5 & .65 & \\
& POS 6 & .71 & \\
& POS 7 & .65 & \\
& POS 8 & .83 & \\
& CRE 1 & .90 & \\
& CRE 2 & .93 & \\
& CRE 3 & .91 & .91 \\
\hline
\end{tabular}

Note: $\mathrm{AVE}=$ average variance extracted; $\mathrm{POS}=$ perceived organisational support

and 'I am self-assured about my capabilities to perform my work activities'. Cronbach's alpha was .79 (see Appendix for complete items).

POS. We used an eight-item version of the Survey of Perceived Organisational Support, which was developed by Eisenberger, Cummings, Aemeli, and Lynch (1997). Employees answered on a 7-point Likert scale, ranging from 1 $=$ strongly disagree to $7=$ strongly agree. Sample items included 'My organisation really cares about my well-being' and 'My organisation strongly considers my goals and values'. Cronbach's alpha was .71 (see Appendix for complete items).

Creativity. We used a four-item scale from Baer and Oldham (2006). Leaders rated employees' creativity based on a 7-point Likert scale, ranging from $1=$ strongly disagree to $7=$ strongly agree. Sample items included 'This employee suggests many creative ideas that might improve working conditions at the organisation' and 'This employee often comes up with creative solutions to problems at work'. Cronbach's alpha was .94 (see Appendix for complete items).

Factor loadings of all constructs' measurements and average variance extracted (AVE) statistics (Fornell \& Larcker, 1981) are reported in Table 1. Overall, the AVE statistics of all constructs were above the recommended cutoff of .50 (Bagozzi \& Yi, 1988).

\section{Analytical Strategy}

Based on the Becker (2005) and Spector and Brannick (2011) argument that the inclusion of control variables should be considered with caution, especially because it can cause unanticipated impacts on the relationships among the main variables, and that the investigation of control variables (e.g., demographics) is only essential when the control variables are the main variables of interest or important, we decided not to draw control variables in the statistical analysis. Our decision is consistent with a previous study (i.e., Walumbwa et al., 2010).

We tested our study model with two interlinking steps. First, we examined the mediating effect of competence on servant leadership and follower creativity (Hypothesis 1-2) using structural equation modelling (SEM) and the bootstrapped indirect effect (Preacher \& Hayes, 2008). We utilised SEM to analyse our study hypotheses since SEM is recognised as an effective method that can examine the whole hypothesised model concurrently while avoiding the accumulation of type I errors (Anderson \& Gerbing, 1988).

Second, we analysed the moderated mediation model (Hypothesis 3) following the bootstrapping procedure suggested by Preacher, Rucker, and Hayes (2007).

\section{Results \\ Confirmatory Factor Analyses and Chi-Square Model Comparison Tests}

We first applied confirmatory factor analysis to ascertain whether the constructs of interest (i.e., servant leadership, follower competence, POS, and follower creativity) were distinctive and to confirm the data fit of the hypothesised model. As indicated in Table 2, the hypothesised four-factor model was deemed a good fit with all fit statistics within acceptable standards, $\chi^{2}(d f=227)=361.61$; RMSEA $=.06$, TLI $=.91, \mathrm{CFI}=.93$. We also examined four alternative nested models, and those fit statistics are also shown in Table 2. We took the first three alternative models into consideration because servant leadership, follower competence, and POS all included responses from followers only, which made the data more susceptible to common method variance. By demonstrating chi-square model comparisons tests (Bentler \& Bonett, 1980), we concluded that the hypothesised model is superior in terms of data fit to the alternative models.

\section{Descriptive Statistics and Correlations}

As shown in Table 3, the correlations among study variables (i.e., follower creativity, servant leadership, follower competence, and POS) were found to be consistent with the theory-based predictions, with the strongest correlation manifested in the relationship between servant leadership and competence $(r=.49, p<.001)$ and the relationship between servant leadership and POS $(r=.49, p<$ .001). Specifically, follower competence was significantly related to servant leadership and creativity $(r=.31, p<$ $.05)$, suggesting the appropriateness of its further analysis as a potential mediator. 
Table 2

Results of Confirmatory Factor Analyses and Chi-Square Model Comparisons Tests

\begin{tabular}{lllllll}
\hline Measurement model & $\chi^{2}$ & $d f$ & $p$ value & CFI & TLI & RMSEA \\
\hline Hypothesised four-factor model & 361.61 & 227 & .000 & .93 & .91 & .06 \\
Alternative 1 (three-factor model) $^{\mathrm{a}}$ & 419.14 & 231 & .000 & .90 & .87 & .07 \\
Alternative 2 (three-factor model) $^{\mathrm{b}}$ & 417.60 & 231 & .000 & .90 & .87 & .07 \\
Alternative 3 (two-factor model) $^{\mathrm{c}}$ & 474.23 & 233 & .000 & .87 & .84 & .08 \\
Alternative 4 (one-factor model) $^{\mathrm{d}}$ & 813.49 & 239 & .000 & .70 & .62 & .13
\end{tabular}

Chi-square model comparison tests

\begin{tabular}{llll}
\hline$\Delta$ Models & $\Delta \chi^{2}$ & $\Delta d f$ & $p$ value \\
\hline Hypothesised model vs. Alternative 1 & 57.53 & 4 & .000 \\
Hypothesised model vs. Alternative 2 & 55.99 & 4 & .000 \\
Hypothesised model vs. Alternative 3 & 112.62 & 6 & .000 \\
Hypothesised model vs. Alternative 4 & 451.88 & 12 & .000 \\
\hline
\end{tabular}

Note: $\mathrm{CFI}=$ comparative fit index; TLI = Tucker-Lewis fit index; RMSEA = root-mean square error of approximation

${ }^{\text {a } T h r e e-f a c t o r ~ m o d e l ~}=$ Servant leadership and competence combined into a single factor.

${ }^{\mathrm{b}}$ Three-factor model = Servant leadership and perceived organisational support combined into a single factor.

${ }^{\mathrm{C}}$ Two-factor model $=$ Servant leadership, perceived organisational support, and competence combined into a

single factor.

${ }^{\mathrm{d}}$ One-factor model $=$ All factors combined into a single factor.

\section{Table 3}

Means, Standard Deviations, Correlations, and Reliabilities

\begin{tabular}{lllllll}
\hline Variable & $M$ & $S D$ & 1 & 2 & 3 & 4 \\
\hline Creativity & 4.66 & 1.09 & $(.94)$ & & & \\
2 SL & 4.81 & .78 & $.36^{* * *}$ & $(.86)$ & & \\
3 COM & 5.19 & .83 & $.31^{*}$ & $.49^{* * *}$ & $(.79)$ & \\
4 POS & 4.59 & 0.65 & .14 & $.49^{* * *}$ & $.41^{* * *}$ & $(.71)$ \\
\hline
\end{tabular}

Note: $N=148$ dyads. $S L=$ Servant leadership; $\mathrm{COM}=$ competence; $\mathrm{POS}=$ perceived organisational support. Figures in parentheses are Cronbach's alphas.

$* p<.05 ;{ }^{* * *} p<.001$

\section{Hypothesis Testing}

Hypothesis 1 postulated that servant leadership is positively related to follower competence. As shown in Model 2, Table 4, Hypothesis 1 was supported, $\beta=.50$, $t(146)=4.54, p<.001$.

To test Hypothesis 2, which posited that follower competence mediates the relationship between servant leadership and follower creativity, we conducted the bootstrapped indirect effect test (Preacher \& Hayes, 2008). The result of the bootstrapped indirect effect test using 5,000 resamples supported Hypothesis 2 because the confidence interval did not include zero ( $95 \%$ bootstrap CI $[.01, .19])$.

In addition, we adopted the SEM method and followed the two-step process suggested by Hair, Black, Babin, and Anderson (2010). We first examined the relationships between study variables, as instructed in Step 1. According to Table 3 , servant leadership was significantly related to follower creativity $(r=.36, p<.001)$, suggesting that the direct, unmediated relationship between the two variables was significant. Servant leadership also established a significant relationship with the potential mediator, follower competence $(r=.49, p<.001)$. Last, follower competence was found to be significantly related to follower creativity $(r=.31, p<.05)$, indicating, together with the afore-

\section{Table 4}

Results of Mediation Test for Structural Models

\begin{tabular}{lll}
\hline Model element & Model 1 & Model 2 \\
\hline Standardised parameter estimates & & \\
$\mathrm{SL} \rightarrow$ Creativity & $.38^{* * *}$ & $.29^{*}$ \\
$\mathrm{SL} \rightarrow$ COM & & $.57^{* * *}$ \\
$\mathrm{COM} \rightarrow$ Creativity & & $.17^{*}$ \\
Model fit & & \\
$\chi^{2}$ & 214.85 & 132.88 \\
$d f$ & 74 & 43 \\
$p$ value & .000 & .000 \\
CFI & .88 & .97 \\
TLI & .86 & .95 \\
RMSEA & .08 & .04
\end{tabular}

Chi-square model comparison test

\begin{tabular}{ll}
\hline$\Delta$ Model & Model 1 vs. Model 2 \\
\hline$\Delta \chi^{2}$ & 81.97 \\
$\Delta d f$ & 31 \\
$p$ value & .000 \\
\hline
\end{tabular}

Note: $N=148$ dyads. $\mathrm{SL}=$ servant leadership; $\mathrm{COM}=$ cmpetence; $\mathrm{CFI}=$ comparative fit index; TLI = Tucker-Lewis fit index; RMSEA = root-mean square error of approximation. Model 1 is the direct effect-only model; Model 2 is the mediation model (hypothesised model).

${ }^{*} p<.05 ;{ }^{* *} p<.01 ;{ }^{* * *} p<.001$

mentioned results, that all the requirements in step 1 were satisfied. In step 2, we attempted to estimate the hypothesised mediation model and identify the mediation type. The results in Model 2 (i.e., the mediation model), shown in Table 4, suggested that after the mediator (i.e., follower competence) was added, the significance level of the relationship between the independent variable (i.e., servant leadership) and dependent variable (i.e., follower creativity) became weaker, that is, $\beta=.38, t(146)=4.60, p<$ $.001 \rightarrow \beta=.29, t(145)=2.58, p<.05$, although it was still significant, suggesting a partial mediation. Taken together, the results confirmed that Hypothesis 2 was supported. 
Table 5

Results of Moderated Mediation Analysis Across Levels of POS

\begin{tabular}{lllllll}
\hline & & & & \multicolumn{2}{c}{$\begin{array}{c}95 \% \text { confidence } \\
\text { interval }\end{array}$} \\
\cline { 3 - 7 } Moderator & Level & $\begin{array}{l}\text { Conditional } \\
\text { indirect effect }\end{array}$ & SE & Lower & Upper \\
\hline POS & Low & .06 & .05 & -.01 & .17 \\
& High & .10 & .06 & .01 & .22 \\
\hline
\end{tabular}

Note: $N=148$ dyads. POS = perceived organisational support. Conditional indirect effects are standardised numbers. Results are based on 5,000 bootstrap samples.

Hypothesis 3 predicted that the indirect effect of follower competence on the servant leadership-follower creativity relationship would be strengthened by a level of POS. To assess moderated mediation, we followed the procedure suggested by Preacher et al. (2007). We first tested whether there was a significant interaction between servant leadership and perceived organisational support in predicting follower competence. The result confirmed the moderating role of POS for the relationship between servant leadership and follower competence, $\beta=.10$, $t(144)=1.69, p=.04$.

We then continued to test the conditional indirect effect of servant leadership on follower creativity, via follower competence, across low and high levels of POS, with high and low levels of POS at one standard deviation above and below the mean score of POS respectively. The results of the bootstrapping procedure suggested by Preacher et al. (2007) for the conditional indirect effect using 5,000 resamples revealed that the conditional indirect effect was stronger and significant (i.e., the interval did not include zero) in the high POS condition (95\% bootstrap CI $[.01, .22])$, but was weaker and neutralised (i.e., the interval included zero) in the low POS condition (95\% bootstrap CI [-.01, .17]); see Table 5. Therefore, Hypothesis 3 was supported.

\section{Discussion}

In this study, we examined a moderated mediation model to address literature gaps in the field of servant leadership, especially regarding follower creativity. We found a significant impact of follower competence as a mediating variable of the relationship between servant leadership and follower creativity. We also found that POS moderated the indirect effect of servant leadership on follower creativity through follower competence. These findings contributed to the theoretical and current empirical knowledge in several ways.

First, we confirmed the significantly positive relationship between servant leadership and follower creativity at the individual level in a new social context. It is undeniable that previous research studies have proven and explained this relationship, but there is still a major limitation in that the current literature on servant leadership and follower creativity is considered to be insufficient in terms of generalisability and reliability. Because our data were collected in an engineering company (i.e., a new in- dustry of research) within the Vietnamese society (i.e., a new culture), we contributed to the improvement of the generalisability of servant leadership and follower creativity. Further, although creativity is considered to be a type of extra-role behaviour, it has received less attention than a fellow construct, organisational citizenship behaviour (Hunter et al., 2013; Neubert et al., 2008; Yoshida et al., 2014), resulting in fewer studies testing its correlation with servant leadership empirically and building the theoretical foundation for this link. Second, to the best of our knowledge, no prior studies have examined the role of follower competence in work tasks in the relationship between servant leadership and creativity. Another study (i.e., Yang et al., 2017) addressed the mediating role of self-efficacy, but it focused on follower creative self-efficacy particularly while competence in our study is regarded as self-efficacy specific to a work role (Spreitzer, 1995). The findings contribute to the current knowledge of servant leadership theory by accentuating servant leaders' ability to promote follower competence such that followers are more likely to engage in creative behaviours.

The final and arguably most important finding of our study is the moderated mediation model, which, to our knowledge, is the first model to consider the role of POS as a potential moderator in servant leadership theory. We proposed and tested the impact of POS on the mediating mechanism, such that when follower POS is high the mediated relationship between servant leadership and follower creativity via follower competence is strengthened, but no significant conditional indirect effect was found when POS is low. This finding might result from the capability of supportive leaders, like servant leaders, to mitigate influence even when POS is low. This capability might manifest itself in the way servant leaders continue to try to create a nurturing working environment for followers as well as they can despite deficiencies in organisational policies or seemingly uncooperative management decisions (Maertz, Griffeth, Campbell, \& Allen, 2007). Because followers mostly interact with leaders in the workplace and are influenced by leaders' behaviours, the way they self-assess their competence and work outcomes depends heavily on the leaders' attitudes. When POS is high, however, support received from other factors within the organisations may provide additional cause for followers to believe in themselves more, which will then lead to their engagement in creative behaviours.

\section{Practical Implications}

The promotion of creativity among employees has been a subject of focus for many organisations concerned with finding prompt and effective responses to a dynamic market environment (Egan, 2005). Aiming to partly address this issue, our study provides practical insights and suggestions, which may be beneficial for organisations seeking to facilitate internal creativity. The major implication for management practices in creativity-oriented 
organisations lies in the critical importance of creating a supportive workplace environment in which employees feel that they receive individualised care and that their work-related competence is enhanced. Therefore, it is suggested that organisations consider selecting and developing servant leaders in significant positions, such that training and recruitment methods both outside and inside organisations is conducted in alignment and mutual communication. Promoting employee competence, then, should become a consistent objective that can benefit organisations by serving as a focal point of leaders' skill advancement and a consistent standard for the appraisal of a leadership training program's success.

Further, our findings suggest that creating a perceived supportive environment to increase employee competence should not be regarded as purely the responsibility of immediate managers, but should also be regarded as a responsibility of other seemingly more distal organisational entities, because employees also include such distal entities in their perception of the working environment. Managers can also play a pivotal role in how employees perceive organisational support (Rhoades, Eisenberger, \& Armeli, 2001; Maertz et al., 2007) by tailoring such support. For example, managers can increase employees' feeling that they are supported by the organisation by communicating to them how much the organisation cares about them and wants them to be successful (Maertz et al., 2007).

\section{Limitations and Future Research}

There were several limitations in this study, indicating areas of future research. First, the servant leadership (i.e., the independent variable), follower competence (i.e., the mediating variable), and POS (i.e., the moderating variable) responses were employees' self-responses, gathered simultaneously. This practice could result in common source bias. Another issue is that the stability of leadership's impact on certain outcomes over time has been raised as an important issue by many scholars (e.g., Mitchell \& James, 2001; Shamir, 2011). Some impacts will become stronger over time, some have their own peaks and remain unchanged, and others will probably experience a decrease after an initial increase. These changes, whether they lie inherently within the leaders or are caused by external factors, affect how we treat the effectiveness of certain leadership styles. Future studies, therefore, should employ a longitudinal design to ascertain how the durability of servant leadership impacts on employee competence and creativity, and an experimental design to examine the causality links of the variables, which would provide valuable academic knowledge and practical implications.

Third, future research could also include other leadership styles such as transformational leadership or charismatic leadership as control variables to further validate the variance in individual and organisational outcomes accounted for by servant leadership. Fourth, our data were collected from only one engineering company in Viet- nam and therefore present a generalisability question for the findings. More research is needed to tackle this problem by conducting studies in other settings within and across other cultures. Fifth, we analysed servant leadership at the individual level, leading to the measurement of this construct as perceived servant leadership. Although this method is appropriate for our main focus in this study, which addresses the gap in psychological mechanisms at the individual level of the servant leadership literature, we suggest that similar research be conducted at the team/group and organisational levels so that the generalisability of the findings can be further confirmed. Sixth, POS was proposed as a potential moderator because, as one of the workplace cues (together with servant leadership), it may be critical in determining follower competence (Ford, 1996); the impact of the interactive effect between POS and follower competence on follower creativity is intuitively plausible and may be worth examining in future research.

Lastly, because recognition of servant leadership has become more popular in many areas of the world and is no longer limited to Western cultures (e.g., Hu \& Liden, 2011; Walumbwa et al., 2010), there is a need for future studies to delve into more perspectives on this leadership style, especially the boundary conditions, including contextual factors and gender issues affecting the relationship between servant leadership and outcomes and the mechanism regulating this relationship. For example, culture-specific values (see Hofstede, 1984; House, Hanges, Javidan, Dorfman, \& Gupta, 2004) may be important moderators that alter follower responses to servant leadership. Further, a study with a larger representation of female leaders is expected to augment the generalisability of our study results by exploring whether leaders' genders can affect follower behaviours and attitudes. Servant leadership, with its participative and cooperative qualities, is arguably more likely to be adopted by female leaders because such leaders tend to exhibit these qualities (Eagly, Johannesen-Schmidt, \& van Engen, 2003), and female leaders are regarded to be more open to unconventional leadership styles, particularly in training and developing followers (Eagly et al., 2003). However, due to stereotypes in favour of masculine qualities in many cultures (Eagly \& Karau, 2002), followers of female leaders may be less likely than followers of male leaders to perform creativity.

\section{Conclusion}

In this study, we investigated the role of servant leadership regarding a desirable follower outcome: creativity. More specifically, we contributed to the current knowledge of how and under what conditions servant leaders can cultivate more creative behaviour from followers. We empirically validated follower competence as a motivational factor that affects the impact of servant leadership on follower creativity. We also found that other factors within organisations, besides leaders, are important in 
determining followers' exhibition of creativity, such that when POS was high it strengthened the role of servant leadership on follower creativity by bolstering the impact of follower competence on follower creativity. This shows that the responsibility to build a supportive and nurturing environment for follower creativity to flourish should not only be held by followers' immediate leaders but should also be fostered by consistent collaboration among policies, departments, and individuals in organisations.

\section{Appendix}

Items Used to Measure Servant Leadership, Competence, Perceived Organisational Support, and Creativity

Servant leadership ( $\alpha=.86$ ); Liden et al. (2014)

1. My leader can tell if something work related is going wrong.

2. My leader makes my career development a priority.

3. I would seek help from my leader if I had a personal problem.

4. My leader emphasises the importance of giving back to the community.

5. My leader puts my best interests ahead of his/her own.

6. My leader gives me the freedom to handle difficult situations in the way that I feel is best.

7. My leader would NOT compromise ethical principles in order to achieve success.

Competence ( $\alpha=.79$ ); Spreitzer (1995)

1. I am confident about my ability to do my job.

2. I am self-assured about my capabilities to perform my work activities.

3. I have mastered the skills necessary for my job.

Perceived organisational support $(\alpha=.71)$; Eisenberger et al. (1997)

1. My organisation cares about my opinions.

2. My organisation really cares about my well-being.

3. My organisation strongly considers my goals and values.

4. Help is available from my organisation when I have a problem.

5. My organisation would forgive an honest mistake on my part.

6. If given the opportunity, my organisation would take advantage of me (R).

7. My organisation shows very little concern for me (R).

8. My organisation is willing to help me if I need a special favor.

Creativity $(\alpha=.94)$; Baer and Oldham (2006)

1. This employee suggests many creative ideas that might improve working conditions at the organisation.

2. This employee often comes up with creative solutions to problems at work.

3. This employee suggests new ways of performing work tasks.

4. This employee is a good source of creative ideas.

\section{References}

Amabile, T.M. (1988). A model of creativity and innovation in organizations. In B.M. Staw \& L.L. Cummings (Eds.), Research in organizational behavior (vol. 10, pp. 123-167). Greenwich, CT: JAI Press.

Amabile, T.M. (1996). Creativity in context. Boulder, CO: Westview Press.

Amabile, T., Conti, R., Coon, H., Lazenby, J., \& Herron, M. (1996). Assessing the work environment for creativity. Academy of Management Journal, 39, 1154-1184.

Amabile, T.M., \& Khaire, M. (2008). Creativity and the role of the leader. Harvard Business Review, 86, 100-109.
Anderson, J., \& Gerbing, D. (1988). Structural equation modeling in practice: A review and recommended two-step approach. Psychological Bulletin, 103, 411-423.

Avolio, B., Walumbwa, F., \& Weber, T. (2009). Leadership: Current theories, research, and future directions. Annual Review of Psychology, 60, 421-449.

Baard, P., Deci, E., \& Ryan, R. (2004). Intrinsic need satisfaction: A motivational basis of performance and well-being in two work settings. Journal of Applied Social Psychology, 34, 20452068.

Baer, M., \& Oldham, G. (2006). The curvilinear relation between experienced creative time pressure and creativity: Moderating effects of openness to experience and support for creativity. Journal of Applied Psychology, 91, 963-970.

Bagozzi, R.P., \& Yi, Y. (1988). On the evaluation of structural equation models. Journal of the Academy of Marketing Science, 16, 74-94.

Becker, T.E. (2005). Potential problems in the statistical control of variables in organizational research: A qualitative analysis with recommendations. Organizational Research Methods, $8(3), 274-289$.

Bentler, P., \& Bonett, D. (1980). Significance tests and goodness of fit in the analysis of covariance structures. Psychological Bulletin, 88, 588-606.

Brislin, R. (1970). Back-translation for cross-cultural research. Journal of Cross-Cultural Psychology, 1, 185-216.

Caniëls, M., De Stobbeleir, K., \& De Clippeleer, I. (2014). The antecedents of creativity revisited: A process perspective. Creativity and Innovation Management, 23, 96-110.

Carmeli, A., Gelbard, R., \& Reiter-Palmon, R. (2013). Leadership, creative problem-solving capacity, and creative performance: The importance of knowledge sharing. Human Resource Management, 52, 95-121.

Carmeli, A., \& Schaubroeck, J. (2007). The influence of leaders' and other referents'normative expectations on individual involvement in creative work. The Leadership Quarterly, 18, $35-48$.

Carter, D., \& Baghurst, T. (2014). The influence of servant leadership on restaurant employee engagement. Journal of Business Ethics, 124, 453-464.

Chen, G., \& Bliese, P. (2002). The role of different levels of leadership in predicting self- and collective efficacy: Evidence for discontinuity. Journal of Applied Psychology, 87, 549-556.

Csikszentmihalyi, M. (1999). 16 implications of a systems perspective for the study of creativity. In R. Sternberg (Ed.), Handbook of creativity (pp.313-335). Cambridge, UK: Cambridge University Press.

Deci, E., Connell, J., \& Ryan, R. (1989). Self-determination in a work organization. Journal of Applied Psychology, 74, 580-590.

Deci, E., Schwartz, A., Sheinman, L., \& Ryan, R. (1981). An instrument to assess adults' orientations toward control versus autonomy with children: Reflections on intrinsic motivation and perceived competence. Journal of Educational Psychology, 73, 642-650. 
Eagly, A., Johannesen-Schmidt, M., \& van Engen, M. (2003). Transformational, transactional, and laissez-faire leadership styles: A meta-analysis comparing women and men. Psychological Bulletin, 129, 569-591.

Eagly, A., \& Karau, S. (2002). Role congruity theory of prejudice toward female leaders. Psychological Review, 109, 573-598.

Eisenberger, R., Cummings, J., Aemeli, S., \& Lynch, P. (1997). Perceived organizational support, discretionary treatment, and job satisfaction. Journal of Applied Psychology, 82, 812-820.

Eisenberger, R., Huntington, R., Hutchison, S., \& Sowa, D. (1986). Perceived organizational support. Journal of Applied Psychology, 71, 500-507.

Egan, T. (2005). Factors influencing individual creativity in the workplace: An examination of quantitative empirical research. Advances in Developing Human Resources, 7, 160-181.

Ehrhart, M. (2004). Leadership and procedural justice climate as antecedents of unit-level organizational citizenship behavior. Personnel Psychology, 57, 61-94.

Ford, C. (1996). A theory of individual creative action in multiple social domains. Academy of Management Review, 21, 11121142 .

Fornell, C., \& Larcker, D. (1981). Evaluating structural equation models with unobservable variables and measurement error. Journal of Marketing Research, 18, 39-50.

Graham, J. (1991). Servant-leadership in organizations: Inspirational and moral. The Leadership Quarterly, 2, 105-119.

Greenleaf, R.K. (1970). The servant as leader. Indianapolis, IN: Robert K. Greenleaf Center.

Greenleaf, R.K. (1977). Servant leadership. New York, NY: Paulist Press.

Greenleaf, R.K. (1998). The power of servant leadership. San Francisco, CA: Berrett-Koehler Publishers.

Hackman, R., \& Oldham, G. (1980). Work redesign. Reading, MA: Addison-Wesley Publishing Company.

Hair, J., Black, W., Babin, B., \& Anderson, R. (2010). Multivariate data analysis: A global perspective (7th ed.). Upper Saddle River, NJ: Pearson.

Hofstede, G. (1984). Cultural dimensions in management and planning. Asia Pacific Journal of Management, 1, 81-99.

House, R.J., Hanges, P.J., Javidan, M., Dorfman, P.W., \& Gupta, V. (Eds.). (2004). Culture, leadership, and organizations: The GLOBE study of 62 societies. Thousand Oaks, CA: Sage Publications.

Hu, J., \& Liden, R. (2011). Antecedents of team potency and team effectiveness: An examination of goal and process clarity and servant leadership. Journal of Applied Psychology, 96, 851-862.

Hunter, E., Neubert, M., Perry, S., Witt, L., Penney, L., \& Weinberger, E. (2013). Servant leaders inspire servant followers: Antecedents and outcomes for employees and the organization. The Leadership Quarterly, 24, 316-331.

Liden, R., Wayne, S., Liao, C., \& Meuser, J. (2014). Servant leadership and serving culture: Influence on individual and unit performance. Academy of Management Journal, 57, 1434-1452.

Liden, R., Wayne, S., Meuser, J., Hu, J., Wu, J., \& Liao, C. (2015). Servant leadership: validation of a short form of the SL-28, The Leadership Quarterly, 26, 254-269.

Liden, R., Wayne, S., Zhao, H., \& Henderson, D. (2008). Servant leadership: Development of a multidimensional measure and multi-level assessment. The Leadership Quarterly, 19, 161-177.

Maertz, C., Griffeth, R., Campbell, N., \& Allen, D. (2007). The effects of perceived organizational support and perceived supervisor support on employee turnover. Journal of Organizational Behavior, 28, 1059-1075.

Mitchell, T., \& James, L. (2001). Building better theory: Time and the specification of when things happen. Academy of Management Review, 26, 530-547.

Mumford, M., Byrne, C., \& Shipman, A. (2009). The thinking of creative leaders: Outward focus, inward focus and integration. In T. Rickards, M. Runco \& S. Moger (Eds.), The Routledge companion to creativity (pp. 279-291). New York, NY: Routledge.

Mumford, M., Scott, G., Gaddis, B., \& Strange, J. (2002). Leading creative people: Orchestrating expertise and relationships. The Leadership Quarterly, 13, 705-750.

Neubert, M., Kacmar, K., Carlson, D., Chonko, L., \& Roberts, J. (2008). Regulatory focus as a mediator of the influence of initiating structure and servant leadership on employee behavior. Journal of Applied Psychology, 93, 1220-1233.

Oldham, G., \& Cummings, A. (1996). Employee creativity: Personal and contextual factors at work. Academy of Management Journal, 39, 607-634.

Parris, D., \& Peachey, J. (2013). A systematic literature review of servant leadership theory in organizational contexts. Journal of Business Ethics, 113, 377-393.

Preacher, K., \& Hayes, A. (2008). Asymptotic and resampling strategies for assessing and comparing indirect effects in multiple mediator models. Behavior Research Methods, 40, 879-891.

Preacher, K., Rucker, D., \& Hayes, A. (2007). Addressing moderated mediation hypotheses: Theory, methods, and prescriptions. Multivariate Behavioral Research, 42, 185-227.

Redmond, M., Mumford, M., \& Teach, R. (1993). Putting creativity to work: Effects of leader behavior on subordinate creativity. Organizational Behavior and Human Decision Processes, 55, 120-151.

Rhoades, L., Eisenberger, R., \& Armeli, S. (2001). Affective commitment to the organization: The contribution of perceived organizational support. Journal of Applied Psychology, 86, 825-836.

Russell, R., \& Stone, G.A. (2002). A review of servant leadership attributes: Developing a practical model. Leadership \& Organization Development Journal, 23, 145-157.

Sagiv, L., Arieli, S., Goldenberg, J., \& Goldschmidt, A. (2010). Structure and freedom in creativity: The interplay between externally imposed structure and personal cognitive style. Journal of Organizational Behavior, 31, 1086-1110. 
Shalley, C., \& Gilson, L. (2004). What leaders need to know: A review of social and contextual factors that can foster or hinder creativity. The Leadership Quarterly, 15, 33-53.

Shalley, C., \& Oldham, G. (1997). Competition and creative performance: Effects of competitor presence and visibility. Creativity Research Journal, 10, 337-345.

Shalley, C., Zhou, J., \& Oldham, G. (2004). The effects of personal and contextual characteristics on creativity: Where should we go from here?. Journal of Management, 30, 933-958.

Shamir, B. (2011). Leadership takes time: Some implications of (not) taking time seriously in leadership research. The Leadership Quarterly, 22, 307-315.

Spector, P., \& Brannick, M. (2011). Methodological urban legends: The misuse of statistical control variables. Organizational Research Methods, 14, 287-305.

Spreitzer, G. (1995). Psychological empowerment in the workplace: Dimensions, measurement and validation. Academy of Management Journal, 38, 1442-1465.

Spreitzer, G. (2008). Taking stock: A review of more than twenty years of research on empowerment at work. In J. Barling \& C. Cooper (Eds.), The SAGE handbook of organizational behavior (pp. 54-72). London: Sage Publications.

Stone, A.G., Russell, R., \& Patterson, K. (2004). Transformational versus servant leadership: A difference in leader focus. Leadership \& Organization Development Journal, 25, 349-361.

van Dierendonck, D. (2011). Servant leadership: A review and synthesis. Journal of Management, 37, 1228-1261. doi:10.1177/0149206310380462

van Dierendonck, D., \& Rook, L. (2010). Enhancing innovation and creativity through servant leadership. In D. van Dierendonck \& K. Patterson (Eds.), Servant leadership: Developments in theory and research (pp. 155-165). New York, NY: Palgrave Macmillan.

Walumbwa, F., Hartnell, C., \& Oke, A. (2010). Servant leadership, procedural justice climate, service climate, employee attitudes, and organizational citizenship behavior: A cross-level investigation. Journal of Applied Psychology, 95, 517-529.

Woodman, R., Sawyer, J., \& Griffin, R. (1993). Toward a theory of organizational creativity. Academy of Management Review, $18,293-321$.

Yang, J., Liu, H., \& Gu, J. (2017). A multi-level study of servant leadership on creativity. Leadership \& Organization Development Journal, 38, 610-629.

Yoshida, D., Sendjaya, S., Hirst, G., \& Cooper, B. (2014). Does servant leadership foster creativity and innovation? A multilevel mediation study of identification and prototypicality. Journal of Business Research, 67, 1395-1404. 